\title{
Carlos de Jesús Becerril Hernández (coord.), Historiografía del Porfiriato. Diversas interpretaciones en torno a un polémico asunto, Universidad Anáhuac, México, 2017.
}

\author{
Iliana Marcela Quintanar Zárate*
}

8 de junio de 2018

\begin{abstract}
$\mathrm{E}$ L régimen de Porfirio Díaz ocupa un lugar en el imaginario colectivo de la sociedad mexicana como aquel en el que prevaleció la política de compadres y el desarrollo de un proyecto económico que abrió la brecha de la desigualdad. Como es conocido, esta visión del porfiriato es producto del discurso legitimador de los regímenes revolucionarios y posrevolucionarios, que fincados en la acérrima crítica de su pasado justificaron su propia existencia. Sin negar el establecimiento de una compleja red política en la que se concedían favores y predominaba la deferencia al mandatario, así como los efectos sociales de la modernización económica, en recientes años, la historiografía se ha abocado al análisis del régimen en su propia dinámica con miras a comprenderlo con cabalidad.
\end{abstract}

Es en un contexto de revaloración, análisis y crítica historiográfica del porfiriato en el que se ubica el libro hoy reseñado. Desde una visión multidisciplinaria, los textos que lo componen se alejan de aquella visión negativa del periodo al dar cuenta de los distintos enfoques en los que se han estudiado la minería, las finanzas públicas, algunos grupos sociales como las mujeres, los migrantes, el marco legal y algunas ideologías como el catolicismo social y el liberalismo. El objetivo del libro es entonces ofrecer una perspectiva de las observaciones realizadas sobre el periodo, en aras no sólo de comprenderlo y racionarlo de la mejor manera, sino de mostrar las posibilidades de análisis que

\footnotetext{
*Facultad de Economía, Universidad Nacional Autónoma de México, Email: ilianaquintanar@gmail.com
} 
ofrecen disciplinas como la economía, la sociología y el derecho con las posibilidades de crear nuevas líneas de investigación sobre temas aparentemente agotados.

Como bien se menciona en el libro, el ámbito económico ha sido uno de los más estudiados del periodo, sin embargo, gracias a los textos de Velasco, Molina y García es posible notar que algunos temas fueron relegados en la historiografía, aun con el importante papel que tuvieron en el proceso de modernización económica.

En su análisis sobre la minería, Velasco menciona que los estudios sobre el sector se han centrado principalmente en el periodo colonial, siendo muy escasos los referidos al siglo XIX. Es posible que esta situación se deba tanto al contexto bélico y político, como a una cuestión de disponibilidad y/o fragmentación de fuentes, pues como es sabido en las primeras décadas del siglo XIX prevaleció un ambiente de incertidumbre ocasionado tanto por los constantes cambios políticos como por la falta de un marco legal regulatorio adecuado para la época, que poco favorecieron el establecimiento y éxito de los negocios. Aquello y un desinterés de algunas autoridades locales por el buen resguardo de sus archivos fungen como obstáculos para la investigación.

Frente al panorama historiográfico poco halagüeño para la primera mitad del siglo xIx, el autor identifica un punto de inflexión en la segunda mitad del siglo, en la que es notoria una transformación cualitativa y cuantitativa que hizo que algunos estudiosos dedicaran sus esfuerzos a analizar el comportamiento del sector. En particular se refiere al cambio institucional acontecido en las décadas de los ochenta y noventa dedicado en buena medida a crear un ambiente de seguridad y de garantía de los derechos de propiedad que promovió la entrada de capitales extranjeros, así como la introducción de innovaciones tecnológicas que influyeron favorablemente en la productividad de la industria y su naturaleza como motor de arrastre de otras actividades económicas mediante la creación de eslabonamientos internos. Con todo, el autor menciona que en la última década el tema minero ha sido poco atendido por la historiografía excepto por algunos trabajos que se dedican al estudio de la acuñación, el patrón monetario y las casas de moneda. Con el fin de establecer puentes interdisciplinarios, el autor menciona que la historia social y cultural, la metodología de redes y la historia de la tecnología debieran ser un elemento a tomar en cuenta para futuras investigaciones. Abonando lo dicho por Velasco, en 2012 Felipe Castro publicó su libro titulado Historia social de la Real Casa de Moneda de México, en el que se propone reconstruir y analizar el origen, situación social y familiar, relaciones laborales, ideas y actitudes de los trabajadores de la Real Casa de Moneda"(p. 13), con lo que abona a la historia social de un aspecto de la industria minera desde la mirada de la microhistoria. 
Aquel cambio institucional que destaca Velasco tuvo efectos favorables también en otros sectores. En su estudio, García Lázaro analiza a detalle las estrategias de los capitales europeos y estadunidenses invertidos para la dotación de electricidad en la Ciudad de México. A partir de este trabajo es posible notar el aprovechamiento del capital extranjero del ambiente de seguridades establecidas durante el porfiriato, además de la utilización de la red de influencias e intereses en el ayuntamiento de la ciudad. De esa manera, empresas como Barron \& Forbes, Siemens y las canadienses, a través de Pearson, gozaron de un clima propicio para el despliegue de sus estrategias con el fin de expandir sus negocios y aumentar sus ganancias. Estrategias entre las que destacan las prácticas monopólicas y el establecimiento de redes de negocios con las autoridades locales. En ese sentido, el trabajo de García aporta al conocimiento del desarrollo del sector eléctrico en la Ciudad de México y también a la comprensión de las tácticas empresariales durante el porfiriato.

Para que aquel clima de seguridad persistiera, una de las principales preocupaciones del régimen y sus funcionarios fue el arreglo de las finanzas públicas, pues de ello dependían no sólo el acceso al crédito internacional, sino la persistencia misma del régimen. Mediante un análisis de la historiografía dedicada al estudio del ámbito fiscal de las finanzas públicas, es decir, los ingresos, el gasto y la deuda, Molina demuestra que, si bien el tema ha sido abordado desde diversas disciplinas, todavía queda mucho por hacer en cuanto a la recepción de los cambios entre los contribuyentes. El estudio de Molina comienza por mencionar los esfuerzos del régimen por elevar la recaudación interna mediante el impuesto del Timbre, el que si bien tuvo los productos esperados por las autoridades fiscales no necesariamente tuvo una buena acogida, de ahí que su implementación fuese de manera gradual . en la medida en la que el gobierno tuvo que enfrentarse con la oposición de los agentes económicos que vieron amenazadas sus ganancias"(p. 29).

Dado que un factor importante en el ámbito fiscal es la negociación entre el gobierno y los contribuyentes, Molina da cuenta del proceso de tensiones que se suscitó entre ellos en cuanto a la abolición de las alcabalas. En ese sentido, Molina destaca que un ámbito poco estudiado en la historiografía es la sociología fiscal, término que me parece necesario definir puesto que puede ser fácilmente confundible con una historia social de la fiscalidad. Generalmente por el término se entiende el estudio de las conductas ciudadanas sobre la tributación que conlleva al análisis del consenso, el marco legal y las prácticas de correspondencia con el Estado fiscalizador. Una vez definido el término habría también que justificar este campo de estudio con la utilización de metodología propia de la sociología. 
Además de estudiar las principales fuentes de ingreso interno, Molina examina los trabajos referidos al sector externo entre los cuales destaca un tipo de análisis que considera la política arancelaria como parte de una política fiscal integral que buscó impulsar el desarrollo económico del país. En esta parte del texto se extraña la ausencia de los trabajos de Sandra Kuntz sobre el tema, entre los que se destaca El comercio exterior de México en la era del capitalismo liberal, 1870-1929, donde la autora muestra a través de una reconstrucción de las series del comercio exterior de México y sus principales socios comerciales, así como de la política comercial del porfiriato que el cambio institucional fue favorable, tanto para la diversificación de las exportaciones como para el desarrollo industrial del país.

Finalmente, en cuanto a la deuda y al gasto, Molina menciona que la producción historiográfica es escasa en el primer caso y casi nula en el segundo. El tema de la deuda, sus arreglos y conversiones, y del gasto han sido estudiados en cuanto a su papel como estrategia para promover el desarrollo económico y para demostrar los esfuerzos del gobierno para construir un Estado moderno.

Aunque no se mencione de manera explícita, los tres trabajos mencionados demuestran que una de las ideas subyacentes en la historiografía ha sido el análisis del paradigma liberal, la adopción y transformación de sus postulados en la política porfiriana. La historiografía sobre el liberalismo decimonónico refiere que estuvo sujeta a una serie de modificaciones, ajustes y grandes renuncias según las circunstancias del momento. De acuerdo con la forma que adopta, se le ha categorizado como liberalismo empresarial (S. Topik), liberalismo desarrollista (E. Beatty, A. Knight), liberalismo conservador (C. Hale), liberalismo pragmático (P. Garner) o liberalismo oligárquico (M. Luna), en todo caso uno de los principales consensos historiográficos al respecto es que hacia finales del siglo XIX el liberalismo doctrinario perdió vigencia como ideología rectora, en buena medida por la influencia de las ideas positivistas, al tiempo que coexistían diversas interpretaciones del término en la época. Aquel viraje en los postulados liberales del gobierno identificado por la historiografía fue objeto de crítica en la última etapa del porfiriato como refiere Chimal en su estudio. A partir del análisis de las posturas de Emilio Rabasa y Toribio Esquivel Obregón, Chimal da cuenta de aquella disputa en cuanto al liberalismo porfirista y sus consecuencias en el país.

Cabe señalar que aun cuando el autor distingue entre la postura científica de Rabasa y la positivista de Esquivel, en realidad ambas tienen un mismo origen: el positivismo mexicano. De ahí que la crítica de Rabasa se concentrara en la inoperabilidad e impracticabilidad de la Constitución (características ya identificadas por Justo Sierra décadas atrás), puesto que según los postulados del positivismo las leyes tendrían que estar acorde a las realidades y no viceversa. En el caso de Esquivel, resulta interesante que, aun autoproclamándose 
como positivista, criticara la ideología del régimen al considerar que "los científicos se habían distanciado de los objetivos del liberalismo $\tau$ basando su postura en el pensamiento liberal doctrinario. Mónica Blanco contribuye al tema con su texto sobre los artículos de Esquivel concernientes a la reforma bancaria de 1908 que dan cuenta de la consistencia de su postura, ya que estableció una disputa interesante con Joaquín Casasús (un científico) en cuanto al papel del Estado en la economía, en donde insistió sobre el alejamiento del gobierno a los postulados del liberalismo. Los diferentes liberalismos en pugna que estudia Chimal muestran el proceso de transformación de la ideología hacia finales del siglo xix, mismo que fungió como antesala al intervencionismo y regulacionismo estatal de los gobiernos posrevolucionarios.

En cuanto al ámbito social, el libro ofrece interesantes análisis sobre la migración, las mujeres y el catolicismo. En su artículo, Moreno destaca la importancia de los migrantes como pieza clave para la construcción de la identidad mexicana en general y las aportaciones de los cubanos en el ámbito político, económico y cultural en particular. La autora menciona que la migración cubana no era esperada, ya que los liberales porfirianos tenían una inclinación por la migración europea, pues la consideraban benéfica tanto económica como culturalmente. Con todo, los cubanos llegaron para quedarse. Debido a que uno de los principales factores para migrar a costas mexicanas fue la guerra hispanoamericana de finales del siglo xIx, los cubanos establecieron sociedades políticas y agrupaciones con fines solidarios que según la historiografía tuvieron muy buena acogida entre la sociedad mexicana. Al respecto, la autora señala que a pesar de que algunos clubes eran críticos de Porfirio Díaz o separatistas, en realidad fueron tolerados por el régimen debido a la posibilidad de que Estados Unidos expandiera su dominio en el Caribe estableciendo en la isla un protectorado y por la posibilidad de entrar en futuras negociaciones comerciales. En cuanto a las aportaciones de los cubanos a la economía, Moreno señala que, a pesar de su incursión de manera activa en el negocio de la industria tabacalera, como comerciantes y empresarios, la historiografía sobre el tema es en realidad escasa. No así para el ámbito cultural, en donde al parecer varios estudiosos se han interesado por destacar las aportaciones de la migración cubana en la introducción de elementos afroamericanos, tanto en la música como en la vida cotidiana, que le han dado un carácter particular a la sociedad veracruzana visible incluso hasta nuestros días.

Sobre las mujeres, Armendáriz destaca su papel en el ámbito privado como actantes clave en el proceso de construcción del Estado-nación. A partir del análisis historiográfico del tema, y de un diálogo con la nueva perspectiva de género, la autora muestra que a pesar de la existencia de un ideal, un "deber ser" femenino, en realidad este era poco alcanzable en las bajas capas de la sociedad. Esto porque en aras de la supervivencia propia y de la familia, las 
mujeres debían entrar al mercado de trabajo, ya fuese en el sector educativo o el industrial. El estudio de Armendáriz demuestra que la historiografía se ha abocado al estudio del papel de la mujer en tanto representantes y reproductoras de los códigos de conducta aceptados en la sociedad, que si bien es importante para la comprensión de la formación del Estado moderno durante el porfiriato, lo cierto es que a decir de la autora " en el campo de la historia e historiografía de la mujer no se ha hecho un esfuerzo por visualizar y detectar en los postulados teóricos y epistemológicos de los trabajos, las discusiones que lleven a una problematización de cómo y desde dónde se ha resignificado la escritura de la historia de las mujeres" (p. 136). En ese sentido la propuesta de la autora resulta interesante, pues se trata de superar la historia de las mujeres para pasar al plano del estudio de la mujer en la historia con perspectiva de género.

Así como Armendáriz intenta establecer un diálogo entre teoría e historia a propósito del estudio de la mujer en el porfiriato, Martínez hace lo propio en su estudio sobre el catolicismo social durante este periodo, pues no sólo se dedica a definirlo, sino también a distinguirlo con el término democracia cristiana con el que parece hay cierta confusión en la historiografía. Si el papel de la mujer se circunscribió a esferas privadas, tal parece que el catolicismo social promovido por la publicación de la encíclica Rerum Novarum fungió como un catalizador importante para la actividad social y cívica de los obreros católicos mexicanos en el ámbito público.

Martínez menciona que los católicos sociales promovieron la formación de asociaciones profesionales con el propósito de establecer un puente intermediario de locución entre el gobierno, los patrones y la clase trabajadora. La historiografía, a decir de Martínez, se ha concentrado en el estudio de las implicaciones que tuvo la publicación de la encíclica, en un contexto en el que la relación Estado-Iglesia vivió una breve etapa de conciliación, así como a analizar los argumentos de la ideología en contra del paradigma liberal. No obstante, cabe señalar que el catolicismo social estableció las bases para las movilizaciones de derecha en los años veinte y treinta del siglo xx, Martínez menciona que el interés sobre el tema ha decaído en los últimos años. La observación no es menor, pues tal parece que el argumento del consenso y la conciliación entre Iglesia-Estado durante el porfiriato se repite constantemente en la historiografía sin un análisis profundo de la compleja relación entre la sociedad y las instituciones eclesiásticas y civiles.

El trío de trabajos mencionados sobre aspectos sociales del porfiriato evidencian que uno de los tantos beneficios de una aproximación interdisciplinaria al estudio del pasado es la posibilidad de comprender a cabalidad una realidad concreta mediante la aplicación de una perspectiva teórica para su aná- 
lisis. Desde una mirada distinta, se revalora la aportación de grupos sociales tales como las mujeres, los migrantes y los católicos en el proceso de formación del Estado porfiriano.

Como ya mencioné, otro de los objetivos del libro es alejarse en buena medida de la forma tradicional de estudiar al porfiriato, es decir desde la ciencia política. No obstante, se incluye un texto en el que se analiza la elite política del estado de Sonora. Resulta interesante que aun cuando Grijalva señala que todavía pesa una especie de leyenda negra sobre algunos de sus miembros, lo cierto es que la historiografía sobre el triunvirato sonorense se ha concentrado en su relación con la Guerra Yaqui y la huelga de Cananea. Si bien la autora destaca que existen importantes aportaciones en cuanto a los orígenes de la Guerra Yaqui, los procesos electorales y la desmitificación de Ramón Corral, en la historiografía sonorense persiste todavía "la visión posrevolucionaria del porfiriato poco crítica y poco matizada". Con ello, la autora da cuenta de que el ámbito político todavía es un campo fértil de investigación e interpretación, según la aproximación del historiador.

Como es posible notar, ya sea de manera evidente o tangencial, los trabajos analizan la expresión liberalismo porfiriano, el cambio institucional y la formación del Estado-nación. Es decir, el proceso de modernización política y económica acontecido en el régimen, el cual no podría haber tenido lugar sin la formación de un ordenamiento legal, ya que "era necesario poner en marcha un marco legal que favoreciera -o permitiera- el desarrollo nacional, reorganizara y protegiera los derechos de propiedad, intentando al mismo tiempo su uniformidad a lo largo del país por encima de las legislaciones estatales" (p. 61). En ese sentido, resulta primordial la historia del derecho y de las instituciones jurídicas para el entendimiento de la dinámica propia del régimen. $\mathrm{Al}$ respecto, Becerril menciona que la historia del derecho es mucho más que el estudio de la legislación, el concepto refiere tanto a los ordenamientos legales como a las instituciones jurídicas que los aplican e interpretan y a la cultura jurídica de la que emanan. La historia del derecho es poco cultivada en nuestro país, por lo que el trabajo de Becerril resulta bastante sugerente en cuanto a las posibilidades que ofrece para la comprensión del ámbito público y privado en el Porfiriato.

Después de esta breve reseña del contenido del libro, quedan claras sus aportaciones a la historiografía. En primer lugar, los estudios dan cuenta de lo estimulante y enriquecedor que puede ser un curso de doctorado, ya que son producto del seminario "Historiografía de la segunda mitad del siglo XIx". En segundo lugar, que revisitar un viejo tema desde otras perspectivas disciplinarias abre mucho más el abanico en cuanto a posibilidades de investigación, fuentes y modelos teóricos a utilizar para comprender la realidad que se estudia. En tercer lugar, que es urgente ampliar el espectro de estudio y salir del 
provincialismo citadino que todavía persiste en la historiografía, pues las experiencias regionales resultan ser útiles para matizar el desarrollo de tal o cual proceso nacional.

Para finalizar, me gustaría mencionar que, si bien los trabajos hacen un análisis detallado de la historiografía de cada tema, a manera de complemento para la discusión y actualización de los trabajos, valdría la pena revisar no sólo publicaciones en revistas de instituciones localizadas en la Ciudad de México, sino de centros de investigación ubicados en los estados de la república, pues es necesario establecer un vínculo entre lo local, lo regional y lo nacional. Por otro lado, resultaría útil también realizar una exhaustiva búsqueda en las tesis de grado, ya que es bien sabido que la elección de los temas responde en buena medida a la discusión historiográfica del momento en el que se realizan, por lo que resultan ser un buen observatorio para conocer las tendencias historiográficas actuales. 